\title{
Hosetsu-dwarf; Useful Rice for Molecular Biological Research on Plant Seed Development
}

\author{
Akihiro KURITA' ${ }^{1}$, Mitsuaki ITOH', Sousuke TAKENAKA', Hideshi MAKINO', \\ Shigeto MORITA ${ }^{1,2}$, Takehiro MASUMURA ${ }^{1,2 *}$ and Kunisuke TANAKA ${ }^{1,2}$ \\ Laboratory of Genetic Engineering, Faculty of Agriculture, Kyoto Prefectural University, \\ Shimogamo, Kyoto, 606-8522, Japan \\ ${ }^{2}$ Kyoto Prefectural Institute of Agricultural Biotechnology, Seika-cho, Kyoto, 619-0244, Japan \\ *Corresponding author E-mail address: masumura@kpu.ac.jp
}

Received 28 October 2001; accepted 18 December 2001

\begin{abstract}
Rice is one of the most important crops in the world, and thus as a model plant it has been the subject of much research. But many kinds of rice species are not easy to handle in a laboratory space. To investigate the dwarf rice's suitability for experimental work, we analyzed the characteristics of Hosetsu - dwarf. Hosetsu-dwarf has small body size, a short life cycle, and normal seed formation. We established a standard method for its hydroponic cultivation. We found as well that its endosperm polypeptide compositions and the morphological observation were not unusual. Thus we propose that Hosetsu - dwarf is an excellent tool for basic studies of seed development.
\end{abstract}

Keywords: rice, dwarf rice, rice, seed development

\section{Introduction}

The endosperm tissues of cereal seeds are the principal storage organs for protein, oil, and carbohydrate. In other words, cereal endosperm cells are extremely important cells that provide basic food for humankind. Rice is the staple food of most of the world's population, so rice was selected as a model plant for genome science (Sasaki, 1998). Rice, however, is difficult to cultivate in a laboratory environment space. First, its body size creates difficulty in maintaining a large number of plants (ex. standard cultivars Nipponbare) in a limited space. Second, it has a long generation time, with its generation cycle limited to three times a year. Third, rice requires strong light during its seed development stage. For these reasons, it is difficult to maintain standard cultivars all year'round in an artificial environment.

An understanding of the formation mechanisms of the endosperm cell and the accumulation process of storage substances is extremely important in stabilizing world crop production. Rice endosperm cell is a model for basic studies of plant seed endosperm development. Arabidopsis has a remarkably small genome size (Leutwiler, 1984), short life cycle, and easy transformability (Bechtold et al., 1993). These characteristics make Arabidopsis extremely useful in studies of the molecular genetics of higher plants. However, Arabidopsis is a dicotyledonous plant and its endosperm tissue degenerates during seed formation (Mansfield, 1994). So, cereals are more suitable for understanding molecular mechanisms of development of the endosperm tissue than is Arabidopsis. However, cereals have weak points in regard to their use as an experimental material for molecular analysis. These include the large shapes and long life cycles of many cereals, requiring maintenance in a large, controlled greenhouse year 'round. A stable supply of the fresh seeds is necessary in order to study the development of endosperm cells. The quick freezing method (Yamagata and Tanaka, 1986) was designed to preserve the endosperm cell, yet it was difficult to maintain active gene expression when using this method. The use of dwarf-rice as research material would solve the problem of unstable endosperm cell preservation. This paper discusses the worth of Hosetsu - dwarf rice for basic studies of rice endosperm development.

\section{Materials and Methods}

\section{Plant material and growth conditions}

Dwarf rice (Oryza sativa L. cv. Hosetsu-dwarf; Fig. 1A left) was obtained from The Hokkaido 


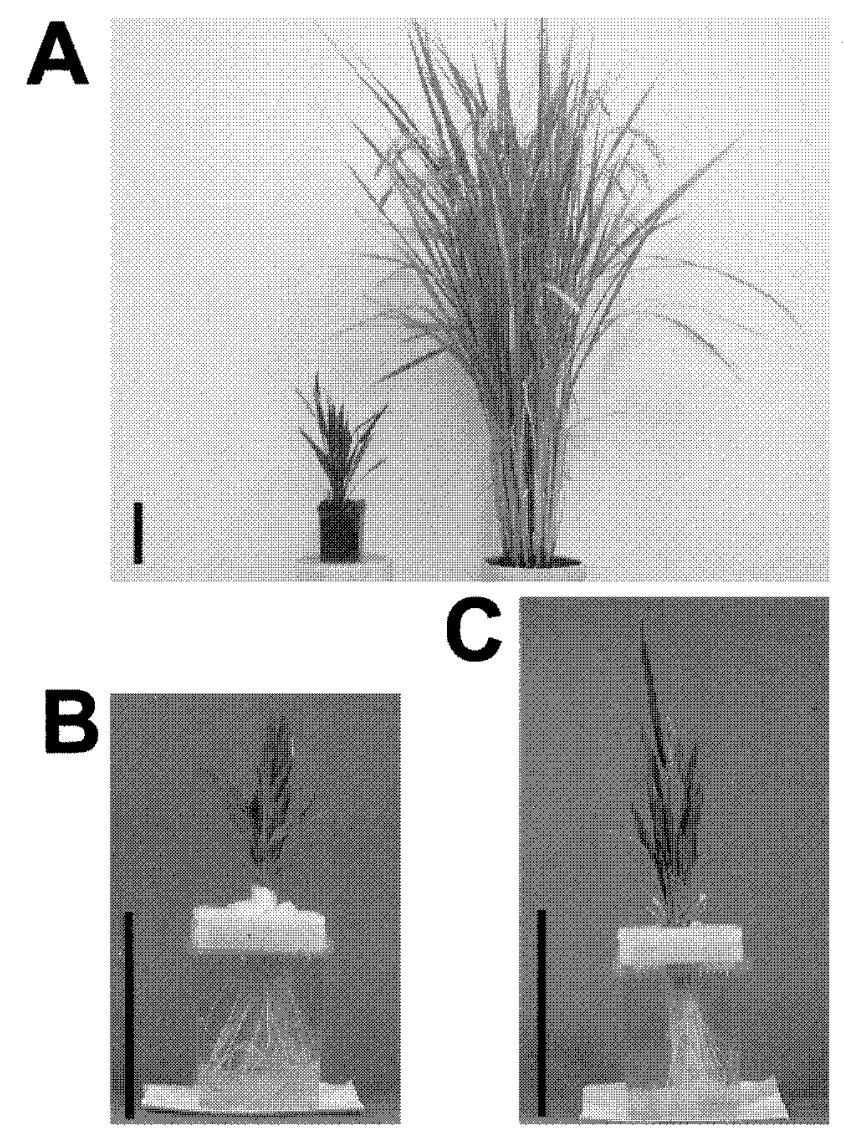

Fig. 1 Shapes of the Hosetsu - dwarf.

(A) Hosetsu-dwarf; 60 days after sowing (left), Nipponbare; 90 days after sowing (right). (B) Two months after sowing. (C) Three months after sowing; seeds are ripening. Scale bar indicates $10 \mathrm{~cm}$.

Prefectural Kamikawa Agriculrural Experiment Station (Japan). Kirara-397, Sasanishiki, Koshihikari, and Nipponbare was obtained from The National Agricultural Research Center of Japan. Seeds were germinated in the dark at $28^{\circ} \mathrm{C}$ for 7 days. Individual seedlings were transplanted from the seedbed to a plastic plant box $(65 \mathrm{~mm} \times 65 \mathrm{~mm}$ $\mathrm{x} 95 \mathrm{~mm}$ ) containing hydroponic nutrient solution (Mae and Ohira, 1981; $1 \mathrm{mM} \mathrm{NO}_{3}^{-}, 0.6 \mathrm{mM} \mathrm{H}_{2} \mathrm{PO}_{4}^{-}$, $0.3 \mathrm{mM} \mathrm{K}^{+}, 0.3 \mathrm{mM} \mathrm{SO}_{4}{ }^{2-}, 0.3 \mathrm{mM} \mathrm{Ca}{ }^{2+}, 0.6 \mathrm{mM}$ $\mathrm{Mg}^{2+}, 45 \mu \mathrm{M}$ ferric tartrate, $0.3 \mu \mathrm{M} \mathrm{Cu}^{2+}, 0.7 \mu \mathrm{M}$ $\mathrm{Zn}^{2+}, 0.9 \mu \mathrm{M} \mathrm{Mn}^{2+}, 5 \mu \mathrm{M} \mathrm{H}_{3} \mathrm{BO}_{3,}, 1 \mu \mathrm{M} \mathrm{MoO}_{3}$ at $\mathrm{pH} 5.5$ ). The nutrient solution was replaced once a week. The basal part of plant was wrapped loosely in cotton wool, which it was then inserted into a hole in a styrene foam plates, which was used as a cover. These plants were cultivated in a growth chamber (MLR-350, SANYO, Japan) with $16 \mathrm{~h}$ light period provided by fluorescent lamps (40, 120 , or $\left.170 \mu \mathrm{mol} \mathrm{m}^{-2} \mathrm{~s}^{-1}\right)$. Plants were maintained at a constant temperature of $22^{\circ} \mathrm{C}, 25^{\circ} \mathrm{C}$, or $28^{\circ} \mathrm{C}$, and a relative humidity of $50 \%$ during day and night.
Rice storage protein extraction and SDS-PAGE analysis

Two grams of mature rice seed without husks were frozen using liquid nitrogen, then ground to a fine powder using a mortar and pestle. Neutral lipids were extracted from the powder using acetone. The defatted powder $(10 \mathrm{mg})$ was suspended in $300 \mu \mathrm{l}$ of albumin extraction solution $(10 \mathrm{mM}$ Tris $-\mathrm{HCl}, \mathrm{pH} 7.5,1 \mathrm{mM}$ EDTA, $1 \%(\mathrm{v} / \mathrm{v})$ Triton $-\mathrm{X}$ $100,50 \mathrm{mM} \mathrm{2-mercaptoethanol).} \mathrm{The} \mathrm{mixture} \mathrm{was}$ centrifuged at $2,000 \mathrm{~g}$ for $5 \mathrm{~min}$. The precipitate was suspended in $500 \mu 1$ of SDS - polyacrylamide gel electrophoresis (SDS-PAGE) sample buffer (62.5 $\mathrm{mM}$ Tris $-\mathrm{HCl}$, pH 7.5 , containing $2 \%(\mathrm{w} / \mathrm{v})$ SDS, $10 \%(\mathrm{w} / \mathrm{v})$ glycine, $4 \%(\mathrm{w} / \mathrm{v})$ urea, and $5 \%(\mathrm{v} / \mathrm{v}) 2$ mercaptoethanol). The sample was mixed and sonicated, then centrifuged at $2,000 \mathrm{~g}$ for $5 \mathrm{~min}$. SDSPAGE was performed according to the method of Laemmli (1970).

\section{Light Microscopy}

Developing rice seeds ( 8 days after flowering [DAF]) were cut longitudinally into thirds using a razor blade after being dehusked. The seed blocks were fixed with $100 \mathrm{mM}$ phosphate buffer, $\mathrm{pH} 7.2$, containing $3 \%(\mathrm{v} / \mathrm{v})$ glutaraldehyde for $3 \mathrm{~h}$ at room temperature. The blocks were then treated with $1 \%$ $(\mathrm{w} / \mathrm{v})$ osmium tetroxide in $100 \mathrm{mM}$ phosphate buffer at $\mathrm{pH} 7.2$ for $1 \mathrm{~h}$ at room temperature. The fixed tissues were washed six times with $100 \mathrm{mM}$ phosphate buffer, dehydrated thoroughly with a graded ethanol series and embedded in epoxy resin using a previously described method (Tanaka et al., 1980). For optical microscopy, $1 \mu \mathrm{m}$ thick sections were cut from the embedded block and mounted on glass slides. These sections were stained with $1 \%(\mathrm{w} / \mathrm{v})$ Toluidine Blue, $0.1 \%(\mathrm{w} / \mathrm{v})$ osmium tetroxide, and $1 \%(\mathrm{w} / \mathrm{v})$ tannic acid or $\mathrm{CBB}$ staining solution $(1 \%$ $(\mathrm{w} / \mathrm{v})$ CBB, 40\% (v/v) methanol, 7\% (v/v) acetic acid), and photographed using a light microscope (BH-2; OLYMPUS, Japan).

\section{Transmission Electron Microscopy}

Ultra-thin sections were prepared from the embedded specimen that was used for optical microscopy. The ultra-thin sections were mounted on 100 mesh nickel grids. They were stained with $2 \%$ (v/v) aqueous uranyl acetate and Reynolds's lead citrate and examined using a transmission electron microscope (JEM-1220; JEOL, Japan) at $100 \mathrm{kV}$.

\section{Results and Discussion}

Growth condition of Hosetsu - dwarf

We examined the growth condition of the Hosetsu 
- dwarf, which was grown using hydroponic methods in an artificial environment. The optimal light and temperature conditions of Hosetsu-dwarf growth were determined by measuring the fresh weight of the whole plant under nine different circumstances. Its fresh weight was heaviest when the Hosetsu-dwarf was grown at $28^{\circ} \mathrm{C}, 170 \mu \mathrm{mol}$ $\mathrm{m}^{-2} \mathrm{~s}^{-1}$. Light intensity is the most important element because the ratio of grain ripening decreases below $120 \mu \mathrm{mol} \mathrm{m} \mathrm{m}^{-2} \mathrm{~s}^{-1}$. The Hosetsudwarf needed a previously reported (Mae and Ohira, 1981) hydroponic solution in order to obtain a fully ripe seed, but it did not require additional fertilizer. The recommendable protocol for cultivation of the Hosetsu-dwarf in an artificial condition is as follows: The seeds were soaked in running water overnight, and then incubated at $28^{\circ} \mathrm{C}$ under dark conditions until germination. The germinating seeds were then transferred to hydroponic solutions and incubated at $28^{\circ} \mathrm{C}$ under $16 \mathrm{~h}$ daylight $(170 \mu \mathrm{mol}$ $\left.\mathrm{m}^{-2} \mathrm{~s}^{-1}\right)$ until the first tiller appeared. After this stage, the plant was grown at $28^{\circ} \mathrm{C}$ under $12 \mathrm{~h}$ daylight $\left(170 \mu \mathrm{mol} \mathrm{m}^{-2} \mathrm{~s}^{-1}\right)$. Two months later, ear formation was began (Fig. 1B). Seed maturation was completed at 3 months after sowing (Fig. 1C). These results suggested that the Hosetsu-dwarf could be cultivated in a laboratory space without necessitating a special environment. Thus fresh endosperm cells can be obtained at any time, allowing various kinds of experiments to be carried out all year'round. The characteristics of Hosetsudwarf and Nippnbare are summarized in Table 1.

\section{SDS - PAGE analysis of rice storage proteins}

We examined whether the Hosetsu-dwarf was suited for research regarding seed storage protein. Rice storage proteins in the starchy endosperm were fractionated by SDS-PAGE, and separated into seven groups with differing migrations: 57, 37-39, $26,22-23,16,13$, and $10 \mathrm{kDa}$ polypeptides. These polypeptides constitute major storage proteins that are accumulated mainly in protein bodies (PBs). Tanaka et al. (1980) isolated two types of PBs in the starchy endosperm; PB-I is differentiated from PBII in terms of globular size and amino acid composition. Seed storage proteins were extracted from five kinds of rice seed samples after the removal of albumin. They were analyzed by SDS-PAGE, and

Table 1 Comparison of growth properties of Hosetsu-dwarf and Nipponbare rice.

\begin{tabular}{|c|c|c|c|c|c|c|c|}
\hline & $\begin{array}{l}\text { Culm } \\
\text { height' } \\
(\mathrm{cm})\end{array}$ & $\begin{array}{c}\text { Panicle } \\
\text { length } \\
(\mathrm{cm})\end{array}$ & $\begin{array}{c}\text { Numbers } \\
\text { of tillers } \\
\text { (no./ hill) }\end{array}$ & $\begin{array}{l}\text { Numbers } \\
\text { of panicles' } \\
\text { (no. / hill) }\end{array}$ & $\begin{array}{c}\text { Kernel } \\
\text { weight } \\
\text { (g/1,000 seeds) }\end{array}$ & $\begin{array}{l}\text { Seedling } \\
\text { to heading } \\
\text { (days) }\end{array}$ & $\begin{array}{l}\text { Numbers of } \\
\text { individual plan } \\
\left.\text { (no. } / 0.3 \mathrm{~m}^{3}\right)^{2}\end{array}$ \\
\hline Hosetsu-dwarf & 14.6 & 5.3 & 6.8 & 5.5 & 19.1 & 60 & 100 \\
\hline Nipponbare & 80.4 & 19.5 & 15.0 & 16.6 & 20.5 & 90 & 6 \\
\hline
\end{tabular}

'Average of 100 individual plants.

$0.3 \mathrm{~m}^{3}$ indicates the volume of the growth chamber.

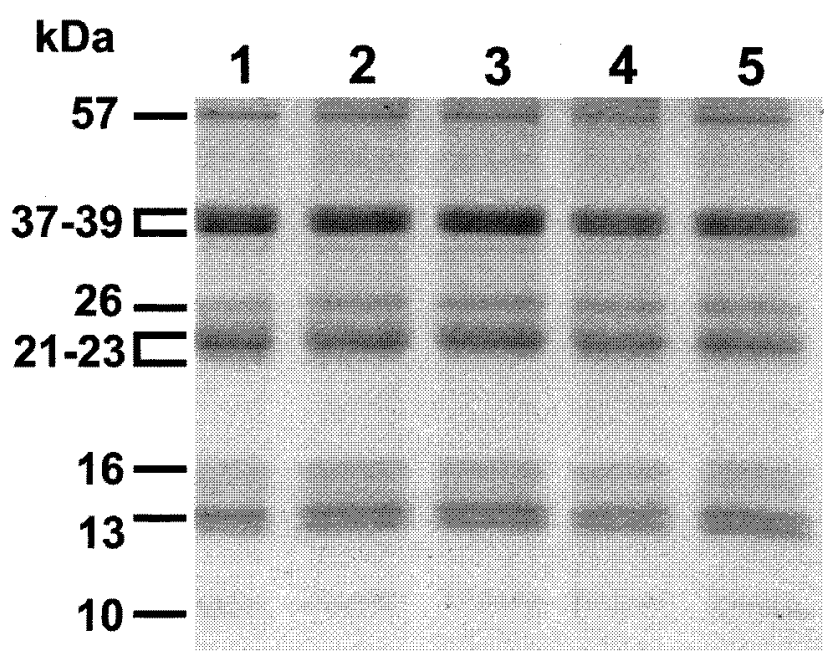

Fig. 2 Comparison of seed storage proteins from Hosetsu-dwarf with other rice cultivars by SDS-PAGE.

Lane 1, Kirara-397; 2, Sasanishiki; 3, Koshihikari; 4, Nipponbare; 5 Hosetsu-dwarf.

Molecular mass is indicated in the left hand margin. 
the band patterns of individual polypeptides were characterized. The band pattern of the storage proteins in the Hosetsu-dwarf showed no difference from those of other japonica rice (Fig. 2).

\section{Microscopic observation of endosperm tissue}

Fig. 3A shows a transmission electron micrograph of the sub-aleurone cell of the Hosetsu-dwarf at 8 days after flowering. The PB has been classified into two types based on shapes revealed by transmission electron microscopy (Tanaka et al., 1980). PB - I has a spherical and concentric ring structure. The surface of the PB-I membrane (arrow head) with attaching polysomes is continuous to the rough endoplasmic reticulum. In contrast, no polysomes were observed attached to the surface of developing PB-II (arrow). Small vesicles similar in electron density to PB-II were observed near the PB-II. Fig. 3B shows the shapes of starch and lipid grains of the Hosetsu-dwarf. These observations agree with those of our previous electron microscopy of endosperm tissues of standard rice (cv. Koshihikari) (Yamagata and Tanaka, 1986).

The molecular mechanism of endosperm cell formation is one of the important research issues in seed development. Morphological observations of the developing endosperm cell have been performed abundantly in regard to various monocots (Olsen et al., 1995; Brown et al., 1996; Olsen, 1998). So, we observed the cross section of endosperm tissues under a light microscope in order to characterize the Hosetsu-dwarf's seed development. Numbers of aleurone layers were observed on the ventral side and the dorsal side of the endosperm tissue. Aleurone cells are small cubic shapes having a thick cell wall and contain a number of aleurone grains and lipid bodies (Fig. 3C). On the other hand, starchy endosperm cells are larger than aleurone cells, which have a thin cell wall, and the sizes of the outer endosperm cells are proportionally larger than the inner endosperm cells. The inside parenchymatous cell in particular contains many starch grains. These observations indicate that the structures of endosperm cells of the Hosetsu-dwarf are substantially identical to those of the usual japonica rice (Hoshikawa, 1993). This information indicates that the Hosetsu-dwarf can provide equally useful material for research on the molecular biology of seed formation.

\section{Valuable characteristics of Hosetsu-dwarf}

The height of the Hosetsu-dwarf is the shortest (substantially $20 \mathrm{~cm}$ ) among the dwarf-type species. The Hosetsu-dwarf is a defect gene mutant $\left(\mathrm{d} 18^{\mathrm{h}}\right)$ in the gibberellin biosynthesis pathway

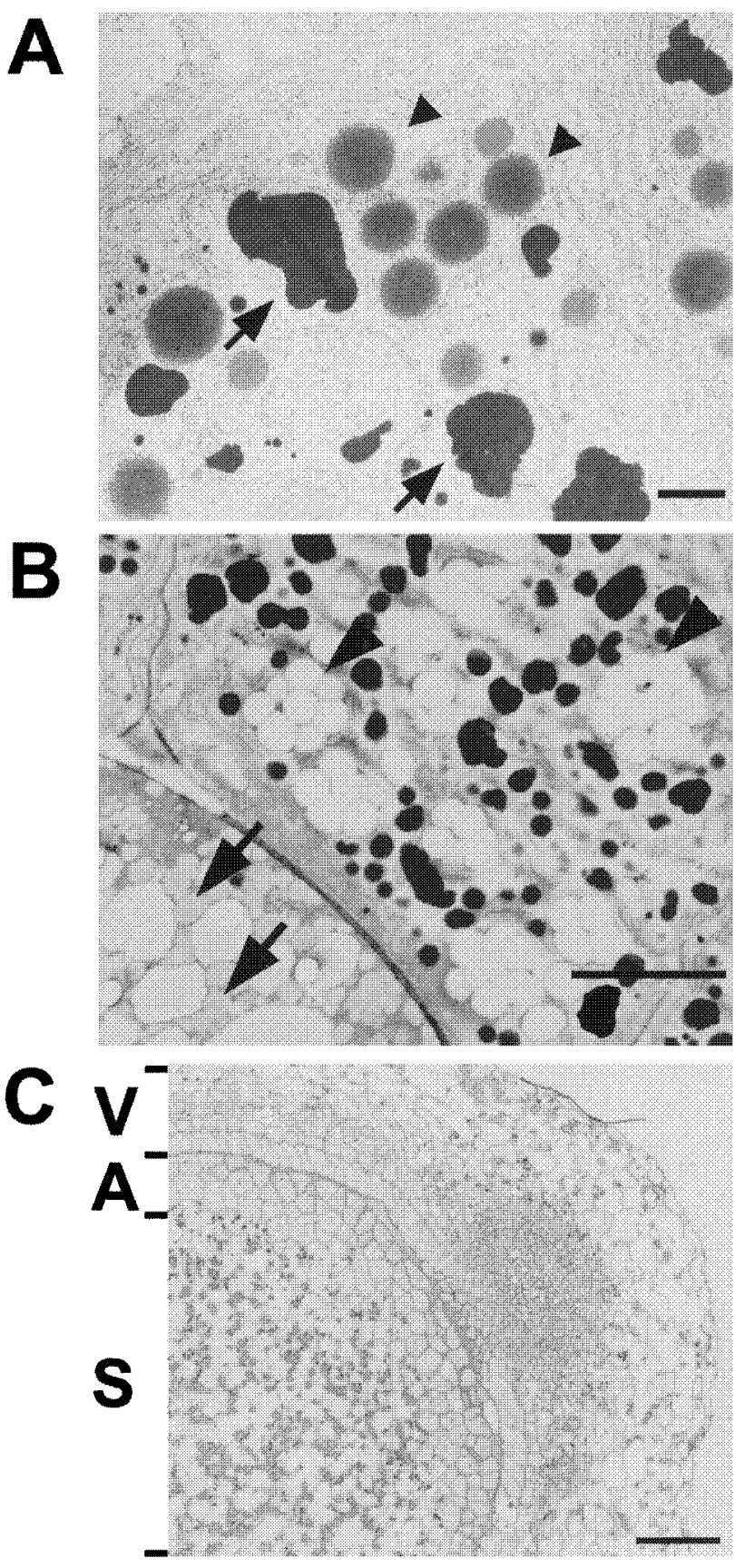

Fig. 3 Transmission electron microscopic and light microscopic images of the starchy endosperm tissues.

(A) Transmission electron micrograph of a developing endosperm cell (8 DAF).

PB-I, (arrow head), PB-II (arrow). Scale bar indicates $1 \mu \mathrm{m}$.

(B) Transmission electron micrograph of a developing endosperm cell and aleruone cell (10 DAF) (low magnification). Starchy granule (arrow head), oil body (arrow). Scale bar indicates $5 \mu \mathrm{m}$.

(C) Light microscopic image of the ventral side of the starchy endosperm tissues of Hosetsudwarf rice seed (8 DAF). A, aleurone layer; S, starch storage cells; V, vascular. Scale bar indicate $100 \mu \mathrm{m}$ 
(Shinbashi et al., 1976; Suge, 1978). The size of its panicles is comparable to those of the usual rice varieties, and the shapes of its kernels are almost the same. We also checked its response to gibberellin A3. When gibberellin A3 $\left(2.5 \mathrm{mg} \mathrm{l}^{-1}\right)$ was provided continuously in the hydroponic nutrient solution, the height and seed numbers became equal to the parent Hosetsu cultivars (data not shown). It is suggested that the inhibitory effect of gibberellin deficiency is very small in the reproductive organs.

The transformation of the Hosetsu-dwarf was succeeded by the currently established Agrobacterium mediated method (Hiei et al., 1994). For example, the human interferon $\alpha$ gene driven by a $35 \mathrm{~S}$ promoter was introduced in the Hosetsu-dwarf (data not shown). So, we concluded that the Hosetsu -dwarf is very useful material for molecular biology and genome research, because large numbers of individual Hosetsu- dwarfs that have a short generation time could be maintained within a limited space, allowing analysis of the functions of unknown genes using enhancer trapping (Meisser et al., 2000) or activation tagging (Hayashi et al, 1992). The Hosetsu-dwarf is normally grown in an artificial environment, and its life cycle is very short, thus it facilitates the screening of a tagging line many times in a single year. These characteristics make it an efficient system for screening large numbers of transgenic plants and treating them under various artificial environments. Simply put, the competence of Hosetsu-dwarf rice could be equal to that of Arabidopsis. We believe that Hosetsu-dwarf could play an important role as the standard material for studies in plant seed science.

\section{Acknowledgements}

This work was supported by grants from the Ministry of Education, Culture, Sports, Science, and Technology (Japan), and from the "Research for the Future" Program of the Japan Society for the Promotion of Science.

\section{References}

Bechtold, N., Ellis, J., Pelletier, G., 1993. In planta Agrobacterium mediated gene transfer in Arabidopsis thatiana based on the maize transposable element $A C$. Theor. Appl. Genet, 84: $371-383$.

Brown, R. C., Lemmon, B. E., Olsen, O-A., 1996. Devel- opment of the endosperm in rice (Oryza sativa L.): cellularization. J. Plant Res., 109: 301-313.

Hayashi, H., Czaja, I., Lubenow, H., Schell, J., Walden, R., 1992. Activation of plant gene by $\mathrm{T}-\mathrm{DNA}$ tagging: Auxin-independent growth in vitro. Science, 258: 1350 $-1353$.

Hiei, Y., Komari, T, Kubo, T., 1994. Transformation of rice (Oryza sativa L.) mediated by Agrobacterium and sequence analysis of the boundaries of the T-DNA. Plant J., 6: 271-282.

Hoshikawa, K., 1993. Anthesis, fertilization and development of caryopsis. In: Matsuo, T., Hoshikawa, K. (Eds.): Science of the Rice Plant Vol. 1, Morphology, pp. 359-374, Nobunkyo, Tokyo.

Laemmli, U. K., 1970. Cleavage of structural proteins during the assembly of the head of bacteriophage T4. Nature, 227: $680-685$.

Leutwiler, L. S., 1984. The DNA of Arabidopsis thaliana. Mol. Gen. Genet., 194: 15-23.

Mae, T., Ohira, K., 1981. The remobilization of nitrogen related to leaf growth and senescence in rice plants (Oryza sativa L.). Plant Cell Physiol., 22: 1067-1074.

Mansfield, S. G., 1994. Endosperm development in Arabidopsis. In: Bowman, J. (Ed.): An Atlas of Morphology and Development, pp. 385-401. Springer-Verlag, New York.

Meissner, R., Chague, V., Zhu, Q., Emmanuel, E., Elkind, Y., Levy, A. A., 2000. A high throughput system for transposon tagging and promoter trapping in tomato. Plant J., 22: 265- 274.

Olsen, O-A., Brown, R. C., Lemmon, B. E., 1995. The role of cytoskeleton in barley endosperm cell wall deposition. Bioassays, 17: 803-812.

Olsen, O A., 1998. Endosperm development. Plant Cell, 10: $485-488$.

Sasaki, T, 1998. The rice genome project in Japan. Proc. Natl. Acad. Sci. U. S. A., 95: $2027-2028$.

Shinbashi, N., Kinoshita, T., Takahashi, M., Hasebe, K., 1976. Genetic aspects of two dwarfs "Hosetsu-dwarf" and "Kotake-tamanishiki" and their character expression-Genetical studies on rice plant. LXVI - Mem. Fac. Agr. Hokkaido Univ., 10: 69-75.

Suge, H., 1978. The genetic control of gibberellin production in rice. Jpn. J. Genet, 53: $199-207$.

Tanaka, K., Sugimoto, M., Ogawa, M., Kasai, Z., 1980. Isolation and characterization of two types of protein bodies in the rice endosperm. Agric. Biol. Chem., 44 : $1633-1639$.

Yamagata, H., Tanaka, K., 1986. The site of synthesis and accumulation of rice storage proteins. Plant Cell Physiol., 27: 135-145. 